\title{
Internship programmes - bridge between school and professional life
}

\author{
Simona Irina GOIA (AGOSTON) \\ The Bucharest University of Economic Studies, Bucharest, Romania \\ simona.goia@ase.ro \\ Ramona Stefania IGRET \\ The Bucharest University of Economic Studies, Bucharest, Romania \\ Cristian Virgil MARINAS \\ The Bucharest University of Economic Studies, Bucharest, Romania
}

\begin{abstract}
All stakeholders involved in the academic educational process (e.g. students, universities, organizations, state institutions) have a direct interest in developing appropriate skills among students aimed at increasing their employability chances on the very competitive labour market and in the same time lessening the transition from school to professional life. Qualitative internship programs are considered a useful instrument which can be used in order to achieve the aforementioned objective. In the last years in Romania this field boomed, many internship programs emerged and were developed and tailored according to specific needs of certain domains. This growth was triggered of one hand side by the initiatives of the socio-economic environment but also by incentives offered by the public sector in form of financing the development of such programs in universities. Which are the main characteristics of internship programs? How are they identified and structured? Which are the factors that influence their quality from students' perspective? What strategies and measures can be adopted in order to improve the quality of internship programs? The present paper aims at addressing the above questions by analysing the responses of over 450 students which were surveyed within a questionnaire based research conducted in the Bucharest University of Economic Studies in Romania. Various research methods - starting with the analysis of descriptive statistics and continuing with factor analysis and regression analysis- were used in order offer an overview - as comprehensible as possible- of the situation of internship programs in various sectors in the field of business, economics and administration. The outcomes of the study can be of interest for several groups of stakeholders and can be taken into consideration when formulating and proposing improvement recommendations of the policies, regulations and operational measures in this field.
\end{abstract}

Keywords: quality of internships, features of internship programs, business and administration students, Romania, questionnaire based survey.

\section{Introduction}

The importance of internship programs which facilitate the transition from school (university) to professional life is widely acknowledged by all stakeholders involved in the educational process (students, universities, companies, public institutions etc.). However, although many universities loudly speak about the value of internships, they rarely provide valuable institutional support, unless there is potential monetary gain (Bay, 2006). Arguably, we believe that the involvement of private and public institutions as internship providers is higher and that the preoccupation for quality internships is seen as a corporate social responsibility policy. For students internships are real professional challenges. 
Besides the effective professional experience they gain, the interns report other significant learning outcomes like personal and interpersonal skills (Beck and Halim, 2006).

In the business and administration field of study, there is a common understanding of the fact that academic curricula should be aligned with the necessities and expectations on the labour market and anticipate the need to develop new skills at students according to future economic, social and technological development. In order to connect students with the business environment from early stages of their academic education and therefore increase their employability (Cantaragiu and Hadad, 2013), in the last years in Romania there were designed and implemented various programs/financing schemes aimed at enhancing the importance and accessibility of internship programs. However a properly documented evidence of the main traits and the qualitative issues of the internships conducted within these programs is not easy to trace.

The present paper tries to tackle this gap in the literature by presenting the results of a questionnaire based survey conducted among over 450 Romanian students from the field of business and administration. The questionnaire approaches various fundamental questions related to internship programs which will be presented in the next part of the article. The paper has the following structure: the literature review focuses on depicting in a synthetic and comparative way various studies related to the role, scope and traits of internship programs. The focus will lie on studies conducted in Romania in various fields of study/activity. Next it will be presented the research methodology and the findings will be discussed. The conclusions of the paper summarize the main ideas, emphasize the contribution of the paper to knowledge advancements and potential for future development of the current research.

\section{Literature review}

Student internships play a significant role in transforming business students to ready-touse professionals in different fields of business activities. Actually, some specialists even consider internships as supervised practical training (Beck and Halim, 2006), smoothly integrating graduates on the labour market. The scientific literature in the field of education is widely addressing the challenges met by companies, universities and students in order to provide, coordinate and graduate such integrated programmes.

Arguably, the main reason internships became such a worldwide fashion is related to the existent gaps between acquired knowledge and its applicability. Authors state that these gaps make the university learning process incomplete and determine different industries to spend money to retrain graduates (Prabhu and Kudva, 2016). Therefore, we consider internships a means of reducing these gaps and built those "ready-to-use professionals" (Prabhu and Manikandan, 2009), increasing the employability of recent graduates.

From the perspective of employers, internships can be considered a new recruitment tool (Knemeyer and Murphy, 2002), while being also a corporate social responsibility initiative. Besides finding new valuable entry level candidates, the organisations build through internships their employer of choice brand and market the image, the products and services of the company.

Internships are more and more perceived by students as salient contribution to their business knowledge. They develop skills in "learning how to learn" in their future professional career (Beck and Halim, 2006) and they become conscious of what kind of 
work they like. Last but not the least, students who experienced working life though internships received more job offers as the internship programme is generally considered valuable professional experience (Ramos, 1997).

From the perspective of universities, they validate through internships their learning curricula, can improve the offer of different lectures and increase their business awareness.

Research in the field of internships emphasises the relationship between internship participation and student employment marketability (Gault et al., 2010). Specialists empirically test the value of the internship experience as a realistic employee preview and career preparation. As other authors stated, after an internship programme, the graduates are better prepared to become employees and have more realistic expectations in regards to their professional life (Prabhu and Kudva, 2016; Yong, 2012; Knouse et al, 1999). However, not all of the internship programmes are well developed and conducted. The management of some internship is quite challenging (Ruhanen et al., 2013). Young people require special attention, especially when we speak about their first working experience. The quality of some internships is discussable and the expectations of students are not met. Some companies are organising internships just to take advantage of unpaid workforce. The quality of an internship is defined by the practical learning experience, the supervisor's capacity to advise and coordinate the interns' activity or the host organisations' practices and policies (Honan and Talmadge, 1979; Beard and Morton, 1999; Garcia and Puig, 2011). A study conducted in Malaysia about the students' perception of industrial internship programme suggests that students also rated favourably the pre-placement activities and assistance coordinated by a special created department, the Students' Industrial Internship Unit (Renganathan et al., 2012). Such a department can enhance the quality of the programme and facilitate the placement of interns.

\section{Research methodology}

The target group of the present research is represented by students (Bachelor and Master level) of the Bucharest University of Economic Studies, one of the most prestigious and representative institutions for higher education in Romania. In order to maximize the response rate the questionnaire was distributed both in physical and electronic form (on a specialized online platform developed for this goal) and most of students were personally approached by the researchers involved in the process.

Most of the questions were closed ones: multiple choices answers or graded on a Likert scale from 1 (strongly disagree) to 5 (strongly agree). The questionnaire was divided into four main parts: the first section contains identification questions related to the age, gender, field of studies, level of studies etc). The second part of the questionnaire aims at outlining as precisely as possible the main traits of the internship programs: type of organization where the internship has been conducted, the length of the internship, the remuneration method if any, the methods through which the internship was identified etc. Data obtained in the first two parts was analysed using mainly descriptive statistics. The third part of the questionnaire is the most extensive one and investigates by means of factor analysis the various dimensions (factors) which directly and indirectly influence the quality of internships programs according to students' opinions. By running the factor analysis resulted five factors, namely: Job arrangements, Mentorship and employability benefits, Learning content, Academic supervision, Bureaucracy and accessibility. These five factors were further used to build a regression model which measures the influence exerted by 
each of the aforementioned factors (independent variables) on quality of internship programs (dependent variable). The last part of the questionnaire contains open question which aim at assessing the strengths and weaknesses of the internships conducted by respondents, as well as making recommendations for the improvement of the quality of internship programs based on own experience.

The items of the questionnaire resulted mainly from a focus group conducted with several stakeholders: students, professors, representatives of universities and of the business environment. More than 450 valid answers were collected in 2015 and in the next period consequently processed. The present paper focuses mainly on the presentation of several descriptive statistics, but mentions to the factor analysis and regression model are also made. Based on that, further recommendation meant to increase the quality and relevance of internship programs in Romania will be formulated.

\section{Results and discussion}

The demographic profile of respondents reveals that, as expected, the wide majority of students (95\%) are aged between 21-25 years. Regarding the gender, 75\% of the answers come from females - this distribution is also not surprising considering the structure of students from the Bucharest University of Economic Studies. Related to the level of study most of the students (82\%) are enrolled in a Bachelor's program and the rest at a Master's program (research or professional Master).

The present paper tries to establish a correspondence between the fields of activity in which internships are performed and the fields of study. Within the Bucharest University of Economic Studies there are eleven faculties which offer Bachelor's and Master's programs which cover a wide range of subareas in the economic, business and administration field from Marketing to Cybernetics and Business Informatics, from Accounting to Management and Public Administration, from Human Resources to Business Administration in Foreign Languages (English, French and German). It can be observed that while students from certain faculties conduct internships in sectors of activity closely related to their field of study, students from other faculties do not seem to focus on a certain sector and show a broad range of interests.

Therefore, it can be observed that students from the Faculty of Business Administration in Foreign Languages conduct their internships in very diverse fields, such as: advertising, banking, quality management, tourism, consultancy, IT, marketing, event management, social sector etc. This large variety could be explained through the fact that the studies do not have a narrow specialization, but rather a general character, which offers students the opportunity to acquire knowledge from diverse fields related to business administration and engage in various business sectors. In a similar situation are also the students from the Faculty of Management and we consider that similar explanations may apply.

On the other hand side, it can be observed that in the case of students from the faculties of Accounting or Finance and Banking there is a tight correlation between the field of study and the sector where internships are conducted. Most of the students from the Faculty of Accounting make an internship in the accounting or audit field, while students from the Faculty of Finance and Banking make an internship in the banking industry, in financial departments or in organizations which deal with European funds. 
In the case of students from the Faculties of Public Administration and Agribusiness no clear-cut conclusion can be drawn: for agribusiness students sectors such agriculture, alimentation, environment and ecology are indeed prevailing, but of importance are also field such as European funds, public services and banking. Most of the students from the Faculty of Public Administration focus indeed on public management, governance, competition regulations, social services, but areas such as human resources, sustainable development, security, communication, non-governmental sector are also preferred.

The information related to the correlation between the field of study and the sectors where internships are conducted might be of great interest especially for the representatives of faculties responsible with the relationship with the business environment, when searching and selecting internship partners and concluding internship agreements with private and public organizations. At university level the fields of activity which engage the largest number of students are: banking, accounting, human resources, counselling, European funding and public administration. Thus, representatives of the academia should focus on developing strategic partnership with relevant actors from these sectors.

In the next figure is outlined the type of organizations where the interviewed students conduct internships: $37 \%$ of them go to public institutions. This result can be also explained by the fact that in the sample there are many students from the Faculty of Public Administration. On the second place (25\%) are situated the small and medium-sized enterprises (SMEs) although the number of agreements between the university and SMEs is not very large. Surprisingly (probably due to the employer branding campaigns and advertising of various career opportunities one would expect a higher rate)multinational companies rank third (14\%). They are followed by NGOs (7\%), universities and own companies (5\%).Other answers refer to political institutions and parties, international organizations and public institutions etc.

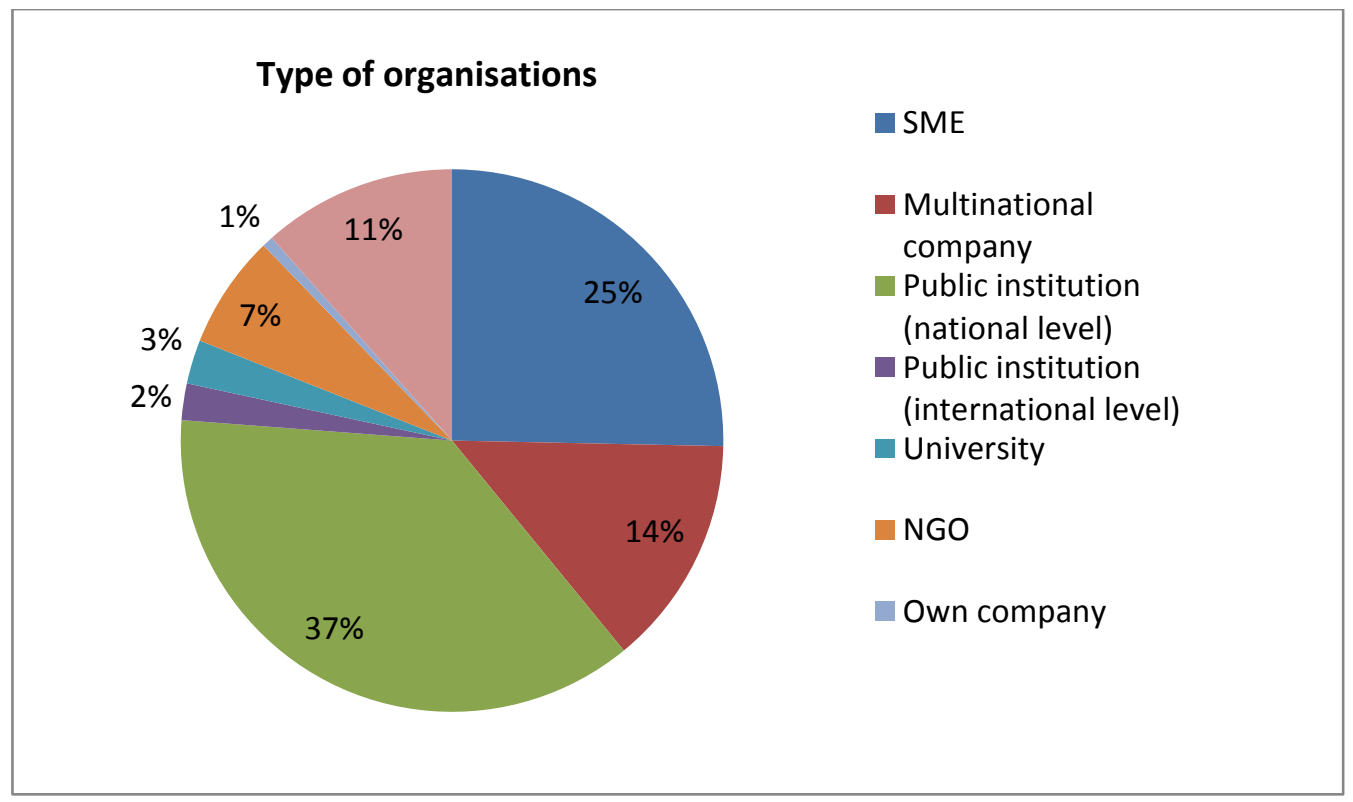

Figure 1.Type of organizations

Source: Own illustration based on collected data. 
Next we present several descriptive statistics related to the remuneration of the internship and how it was identified. As it results from the next figure, the large majority of internships are not paid (almost 70\%). One should note that a more and more important role (over 15\%) is played by European projects conducted by Romanian universities which provide internships for students in companies and offer them subsidies during the project. Only a small number of organizations pay interns from their own resources $(12 \%)$.

PICBE | 423

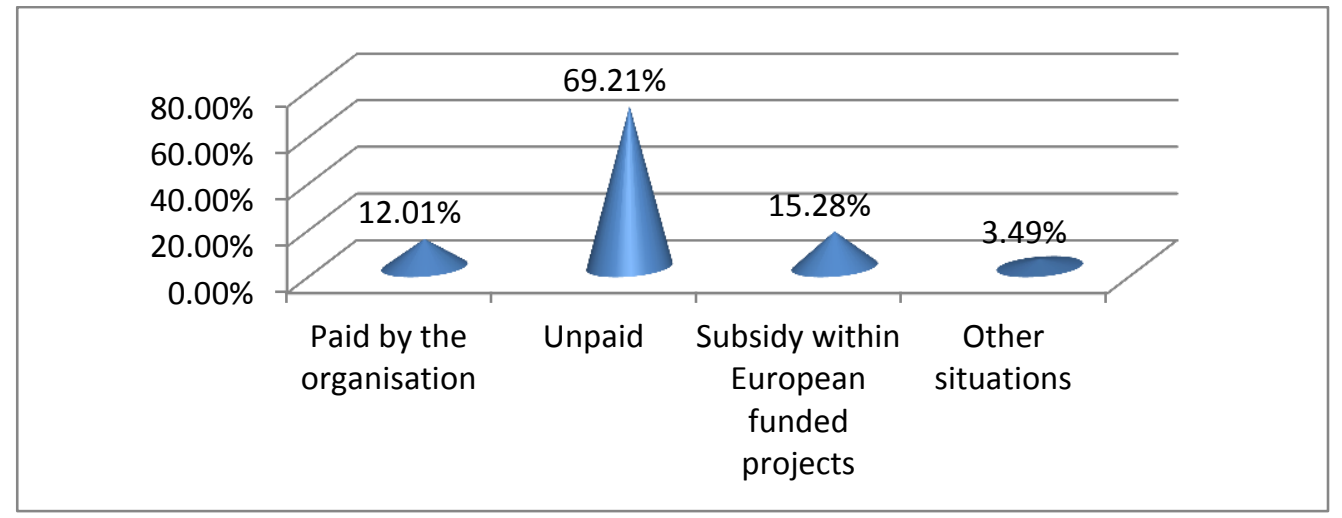

Figure 2. Remuneration of internships

Source: Own illustration based on collected data.

Regarding the identification of the internship programs next Table reveals that most of the internships were found making use of personal network. A very important role is played by the faculty, which provides more than $31 \%$ of the students with an internship position. The involvement of the faculty in this process triggers a positive signal, revealing a more and more close collaboration between academia and companies by establishing partnerships and serving together the interests of students (Dima et al., 2016). Direct applications are also popular, $17 \%$ of the respondents making use of this method. European projects play also an important role, $12.66 \%$ of the students finding an internship within this framework.

Table 1.Identification of internship programs

\begin{tabular}{|l|l|}
\hline How did you identify the internship program? & Percentage (\%) \\
\hline On my own, applying in different organizations & $16.81 \%$ \\
\hline On my own., using my personal network & $34.93 \%$ \\
\hline It was offered by the faculty & $31.22 \%$ \\
\hline Within a project funded by the European Union & $12.66 \%$ \\
\hline Other ways & $4.37 \%$ \\
\hline Total & $100 \%$ \\
\hline
\end{tabular}

Source: own illustration based on collected data.

Regarding the easiness of finding an internship can be observed that for most students it was quite easy to find an internship position: approximately $65 \%$ of the respondents strongly agree ( 5 on the Likert scale) or agree ( 4 on the Likert scale) with the statement: "It was easy for me to find an internship". Just 13\% disagree with the above statement and declare that they faced difficulties when searching for an internship position. Around $20 \%$ of the questioned students have a neutral opinion, meaning that they neither agree nor disagree with the statement. One can assume that the positive outcome depicted above relies also on the fact that respondents are students of one of the most prestigious 
universities for business and economics in Romania and organizations are probably more willing to integrate them and eventually hire them afterwards. Therefore, it cannot be assumed that similar encouraging outcomes would result if the research was conducted in a different university.

However, the analysis of the previous statement does not provide any kind of insights regarding the quality of the internship programs. In order to analyze more in depth the factors which determine the quality of internship programs and to which extend they influence the quality, both a factor analysis and a regression model were developed.

Factor analysis is widely used in social science when we try to measure abstract and complex phenomena. Through factor analysis items which have the same underlying concept are grouped (a kind of clustering of various variables) and several factors result (Craciun et al., 2015). In our case resulted five factors which determine the quality of internship programs: Job arrangements (including items related to working schedule, organization of the internship in the organization, tasks performed), Mentorship and employability benefits (refers to the relation and support offered by the coordinator in the organization and colleagues and relevance of skills acquired for the future career), Learning content (refers mainly to the relationship between theoretical knowledge acquired in school and knowledge needed at the working place), Academic supervision (refers to the relation with the tutor from the faculty and other faculty members), Bureaucracy and accessibility (refers to the paperwork and accessibility to the internship place). Various tests such as Kaiser-Meyer-Olkin (KMO), Bartlett's Test of sphericity, Cronbach's Alpha coefficient were conducted and support the idea that the resulting factors are relevant and well grounded.

In a next stage there were estimated the parameters of the regression model (ordinary least squares) and it resulted that the five independent variables can provide explanations for $53 \%$ of the changes occurred in the value of the dependent variable (namely the quality of internships). All five parameters are positive, meaning that each of the selected factors exerts a positive influence on the quality of internship programs. The biggest influence could be exerted by the factor "Learning content" followed by "Mentorship and employability benefits" and "Job arrangements". Using the regression model stakeholders may become aware of the strategies and measures that should be adopted in order to increase the quality of internship programs.

However this analysis does not represent the main object of the present paper and therefore no detailed information can be provided.

\section{Conclusion}

The main contributions of the present paper refer to the identification of some important traits of internship programs in Romania and therefore allows us to formulate several recommendations for raising the quality of internship programs:

- The companies organising internships should pay more attention to the tasks, duties and responsibilities allocated to interns. Sometimes interns are not integrated in the internships' department teams and become reluctant to take initiative in solving certain tasks;

- The schedule of internship programmes should be adapted in order to respond to students learning curricula; 
- Mentoring is well known as a very important factor in integrating and developing employees; companies organising internships must designate mentors for every intern, increasing the practical learning experience;

- The academic supervisors should be more involved in coordinating and discussing the internship experience. The academia must value internship programmes and improve the learning curricula taking into consideration the students' recommendations;

- The universities actors involved in building internship partnerships with public and private institutions should identify relevant entities for each field of studies; moreover, we believe that the number of partnerships with small and medium size enterprises should increase as our study revealed that a large number of students completed their internships in this type of organisations. Although there is high potential of partnering with multinational companies, their requirements for students are higher and this might be the main reason why only $14 \%$ of our respondents completed their internship programme there.

- The actors involved in organising internships programmes should try to reduce as much as possible the bureaucracy related to these programmes;

- Universities should be open to accept the gap between academic curricula and business practice and try to be more open to cooperation with different kind of companies;

- Organisations should consider budgeting the internship programmes more, especially because sometimes the interns really accomplish important tasks during the stage and can be considered a real workforce inside the company. Although it is not the main purpose of an internship, the financial incentive is a very good motivator.

Another relevant aspect related to the contribution to knowledge advancement refers to the possibility to replicate the research using the available methodology in other fields or geographical areas, if considered appropriate by the fellow researchers. The main limitations of the paper refer actually also to the geographical area (Bucharest, the capital city) and field of activity (business, economics and administration students). While conducted in other region and/or in other sectors of activity very different results might occur.

\section{Acknowledgement}

The survey presented in the present paper was conducted within the project "Human Resources Internships for Students - PREUS", contract POSDRU/161/2.1/G/137915, cofunded from European Social Fund under 2007-2013 Sectoral Operational Program for Human Resources Development.

\section{References}

Bay, J. (2006). Preparing Undergraduates for Careers: An Argument for the Internship Practicum, College English, 69 (2), 134 - 141.

Beard, F.; Morton, L. (1999). Effects of internships predictors on successful field experience, Journal of Mass Communication Educator, 53 (4), 42-53. 
Beck, J.E., Halim, H. (2006). Undergraduate Internships in Accounting: What and how do Singapore Interns Learn from Experience, Accounting Education: an international journal, 17 (2), 151-172.

Cantaragiu, R. and Hadad, S. (2013). The Importance of Play in Overcoming Fears of Entrepreneurial Failure, 14th European Conference on Knowledge Management ECKM, Lithuania, 2013, in Proceedings of the 14th European Conference on Knowledge Management - ECKM, 833-843.

Craciun, L., Nastase, M., Stamule, T., Vizitiu, C. (2015). Leadership in Romanian Small to Medium Enterprises.,Sustainability, 7, 4183-4198.

Dima, A. M., Hadad, S., \& Cantaragiu, R. (2016). A conceptual analysis of business-university knowledge transfers in the energy field. ENERGY, CLIMATE CHANGE AND SUSTAINABILITY, 201-207.

Garcia , R. ; Puig, J. (2011). A Model for Improving the Quality of Student Internship Placements in Engineering Degree, International Journal of Advanced Corporate Learning, 4 (1), 4-11.

Gault, J., Leach, E., Duey, M. (2010). Effects of business internships on job marketability: the employers' perspective, Education + Training, 52 (1), 76-88.

Honan, J.C; Talmadge H.D. (1979). Linking Public Affairs Internships Experience and Academic Studies: a Strategy for Program Design, Southern Review of Public Administration, September, 146-163.

Knemeyer, M.A., Murphy, P.R. (2002). Logistics internships: Employer and Students Perspectives, International Journal of Physical Distribution and Logistics Management, 32 (2), 135-152.

Knouse, S., Tanner, J., Harris, E. (1999). The relation of college internships, college performance and subsequent job opportunity, Journal of Employment Counseling, 36 (1), 35-41.

Prabhu, B.V., Kudva, A. (2016). Success of student Internship in Engineering Industry: A Faculty Perspective, Higher Education for the Future, 3 (2), 164-182.

Prabhu, B.V., Manikandan, K. (2009). Evolution of an effective manufacturing manager, CURIE, 1 (4), 17-31.

Ramos, E. (1997). Internship programs from start to finish, Folio: The Magazine for Magazine Management, 26(6), 38-39.

Renganathan, S., Karim, Z.A., Li, C.S. (2012). Students' perception of industrial internship programme, Education + Training, 54 (2/3), 180-191.

Ruhanen, L., Robinson, R. and Breakey, N. (2013). A tourism immersion internship: Student expectations, experiences and satisfaction, Journal of Hospitality, Leisure, Sport \& Tourism Education, 13, 60-69.

Yong, T. (2012). The mode of theoretical knowledge and practical knowledge combination: the significance of internships, World Journal of Education, 2 (4), 55-63. 